\title{
Compromiso de no RePetición del Estado Colombiano, en el Pos-ACUERdo 2016, UNA FORMA de REPARACIÓN EN TRANSICIÓN, PARA LAS FARC-EP Y LAS NUEVAS Y FUTURAS VÍCTIMAS
}

\section{Commitment of no repetition of the colombian State, in the Post- AgREEMENT 2016, a FORM OF REPARATION IN TRANSITION, FOR THE FARC- EP AND THE NEW AND FUTURE VICTIMS}

Luis Antonio Muñoz Hernández* Trabajo recibido el 2 de noviembre de 2018 y aprobado el 3 de junio de 2019

\begin{abstract}
Resumen
La paz, los conflictos y la justicia transicional como soporte de la reparación. Tema de tradición individual pero complejo al concebirse colectivo. Realidad advertida como resultado parcial de investigación, desde el acuerdo de paz firmado el 24 de noviembre de 2016 entre el Estado Colombiano y el grupo insurgente "fuerzas armadas revolucionarias de Colombia, ejército del pueblo" (FARC-EP) donde se evidencia la existencia de todo un desarrollo dentro de los estándares internacionales de la justicia transicional y del compromiso de no repetición del Estado para de impedir el surgimiento de nuevas víctimas en el del pos-acuerdo generadas por él y por terceros. Una inédita modalidad de reparación integral, figura única a nivel mundial sustentada en: los derechos fundamentales de las generaciones nuevas y futuras y la paz como derecho colectivo y de segunda generación.
\end{abstract}

Palabras clave: paz, conflicto, Derechos Fundamentales, Justicia transicional, reparación integral, no repetición, víctimas, generación futura.

\footnotetext{
Abstract

Peace, conflicts and transitional justice as support for reparation. Theme of individual but complex tradition when conceiving collective. Reality warned as a partial result of the investigation, since the peace agreement signed on November 24, 2016 between the Colombian State and the insurgent group "Revolutionary armed forces of Colombia, army of the people" (FARC-EP) where the existence of all a deve-

* Luis Antonio Muñoz Hernández. Abogado de la Universidad Libre de Colombia Seccional Cúcuta; Magíster en Derecho Procesal de la Universidad de Medellín, Colombia; Magíster en Paz Desarrollo y Resolución de Conflictos de la Universidad de Pamplona Colombia y Granada España; Candidato a Doctor en Derecho Procesal Contemporáneo de la Universidad de Medellín, Colombia. Es Docente Investigador Jornada Completa de la Universidad Libre de Colombia Seccional Cúcuta, Colombia. Además, ejerce la profesión como litigante y consultor en Colombia. Se ha dedicado a ser investigador en temas de Derecho Procesal, Paz, Justicia Transicional y Debido Proceso de Paz desde hace 10 años. Autor de los Libros: Justicia Transicional y la realidad de los procesos de Paz en la Construcción del nuevo orden social en Colombia; y Justicia Transicional y Sustitución Constitucional en Colombia. Caso M-19 (1990).Correo de contacto: luis.munozh@unilibre.edu.co y luismunoz24@msn.com
} 
lopment within the international standards of transitional justice and the commitment of non-repetition of the State to prevent the emergence of new victims in the post-agreement generated by him and by third parties. An unprecedented modality of integral reparation, a unique figure worldwide based on: the fundamental rights of new and future generations and peace as a collective and second generation right.

Keywords: Peace, conflict, Fundamental Rights, transitional justice, integral reparation, non-repetition, victims, future generations.

\section{INTRODUCCIÓN}

Pensar en paz en sentido primario es pensar en lo justo, desde adentro y en cada uno y cuando se exteriorizan, crea el conflicto natural de lo que significa el esquematizar en el exterior sin importar individualidad, el concepto de lo justo ante los ojos de todos y para todos. Amartya Sen en su libro "La Idea de Justicia"1 dice que "la justicia debe conseguirse al ubicar lo injusto, combatiéndolo para descubrir con ello lo justo"2. Otros de inclinación normativa y contractualista como Thomas Hobbes, luego John Locke, Jean-Jaques Rousseau e Immanuel Kant, conciben la justicia en instituciones justas y otros comparatistas, como Smith, Condorcet, wollstonecraft, Bentham, Marx, Jhon Stuart Mill, prefieren que ella sea el producto de una conciliación entre estas instituciones justas y el comportamiento real de la gente.

La Corte Constitucional en sus fallos, ha tenido la misión de adecuar los parámetros de Justicia y en desarrollo de esta función pública debe, con su sabiduría hallar el camino más próximo a la realidad de justicia que en el momento de su decisión se adecúe, noble pero difícil misión, dada la cantidad de vertientes y posiciones que se tejen sobre lo que se considera como justicia3.

Esta realidad, refleja una enorme dificultad para abordar también a la paz, para salirse de ese concepto primario atada con lo justo. La justicia, uno de los objetivos de este artículo, que se recogerá posteriormente y la paz, corren la misma suerte y con el paso del tiempo hacen que las instituciones jurídicas se vayan transformando, al tenor de los nuevos paradigmas evolutivos o involutivos de la humanidad.

Sin embargo, esa reingeniería normativa hoy, no va a la par de los nuevos fenómenos sociales. En tal sentido, vemos como por ejemplo, las estructuras estatales en la gestión y producción de políticas públicas alrededor de la dignidad humana, fallan y la Corte Constitucional suple y actúa en aras de suspender el colapso a través de sus sentencias estructurales. Y lo más difícil de creer, es, que estos cambios sociales se repiten una y otra vez vez, sin que el Derecho la advirtiera y meno las regularla, ni en lo sustancial y ni en lo procesal y cuando se estudian, su alcance no ha sido el más completa o cohesionada con la naturaleza misma de la sociedad. Regular lo humano es inmensamente difícil.

Tal es el caso de la humanidad - paz, como base de la justicia transicional y a su vez, estas dos como base de la reparación integral. Cómo son ellas, cómo se conciben, su evolución, y algunas observaciones sobre las mismas, es el cometido de este artículo con conclusiones tendientes a ilustrar sobre su realidad, en una sociedad liberal, cada vez más desconectada de su interacción con el Estado. En el desenvolvi-

\footnotetext{
$1 \operatorname{Sen}(2010)$

2 Sen (2010), p. 38.

3 Sobre la gran variedad de posiciones argumentativas que abordan el concepto de justicia, además de los nortes referenciados al principio de esta introducción, se puede consultar el ejemplo-ejercicio "Tres niños y una flauta: Una ilustración." En el libro La Idea de Justicia de Amartya Sen, página 44. Allí las posiciones todas válidas y con toda la fuerza argumentativa de: 1. Los utilitaristas, 2. Los igualitaristas económicos y 3. Los libertarios pragmáticos, difieren sobre a cuál de los niños debe dársele una flauta. Sen (2010), p. 44 y 45.
}

MUÑOZ HERNÁNDEZ, Luis Antonio. Compromiso de no repetición del Estado colombiano, en el Pos-Acuerdo 2016, una forma de reparación en transición, para las FARC-EP y las nuevas y futuras víctimas. Revista Justicia y Derecho, Santiago, v. $2, n^{\circ} 1,2019$ 
miento de su exploración e indagación la investigación ha encontrado otras realidades: que el ciclo de la sociedad no es el mismo del ser humano que nace, crece, en ocasiones se reproduce y muere; por su parte la humanidad, conocida como sociedad, nació, ha crecido pero no muere sino que evoluciona o se transforma, por lo que de no tenerse en cuenta la generación futura, se corre el riesgo de su extinción.

\section{Desarrollo conceptual, analítico, hallazgos}

La Constitución Política de Colombia de1991, fue producto de un pacto consensuado entre diferentes corrientes políticas, donde el constituyente como soberano, reconoció el pluralismo, la diversidad étnica y cultural de la nación colombiana; abandonó el Estado de derecho y la primacía de la ley, para dar paso a un Estado Constitucional, reemplazando la hegemonía del principio de legalidad, por la supremacía de la constitucionalidad ${ }^{4}$. Es el Estado colombiano conforme al artículo primero (1), como Estado Social de Derecho cuyos fines expresa en el artículo dos, y entre los cuales se encuentra "... promover la prosperidad general y garantizar la efectividad de los principios, derechos y deberes consagrados en la Constitución", entendiendo la misma como una Constitución material dirigida alcanzar justicia social.

Desde 2010, cuando nada empezaba entre las partes que hoy acordaron la paz, ya el investigador social Mauricio García Durán, hablaba de lo que sería el post-conflicto. Hacía mención de unos retos y estrategias integrales de paz, que sin ellas difícilmente se podrá salir del conflicto. Tanto en la fase del conflicto latente como en fase de postconflicto lo ideal es buscar evitar que este se reactive; disertaba entonces sobre un trabajo de contención del conflicto, (peacekeeping es decir: mantenimiento de paz), cuando este se encuentra en fase de escalamiento y se requiere proteger a la población civil de los efectos del conflicto armado. Explica Montero ${ }^{5}$ tomando plenamente a Johan Galtung y Vicent Fisas:

De acuerdo a la tipología proporcionada por Galtung ${ }^{6}$, la transformación del conflicto se produce vía eliminación de los tres tipos de violencia: violencia directa, violencia estructural y violencia cultural. La eliminación únicamente de la violencia directa nos lleva al peacemaking o al establecimiento de la paz previa negociaciones entre las partes en conflicto: Aquellos esfuerzos, especialmente políticos y diplomáticos, destinados a resolver los conflictos armados o los conflictos que actualmente no están en fase armada, pero que en el pasado sí lo fueron y todavía necesitan negociaciones para llegar a un acuerdo satisfactorio entre las partes. En algunos casos, los procesos de paz intentan transformar las causas de fondo del conflicto a través de las negociaciones?.

Complementa su tesis García, explicando que se pasa de un trabajo de negociar y hacer la paz, (peacemaking es decir: pacificación) que permita poner fin a la confrontación armada a un trabajo de construcción sostenida de la paz (peacebuilding, o Construcción de paz), reconstruir y sanar las heridas dejadas por la guerra en la fase del postconflicto, de forma que se pueda avanzar en las reformas que hagan frente a las exclusiones que subyacen al conflicto. En este contexto, sobre Construcción de Paz se ha expuesto:

Mientras que la transformación del conflicto es el peacebuilding o la construcción de la paz, un proceso que se da a largo plazo y cuya dimensión temporal es más amplia; por ello, el éxito del proceso político de la desecuritización del conflicto armado colombiano dependerá en gran medida del éxito del

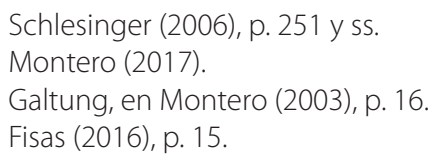

MUÑOZ HERNÁNDEZ, Luis Antonio. Compromiso de no repetición del Estado colombiano, en el Pos-Acuerdo 2016, una forma de reparación en transición, para las FARC-EP y las nuevas y futuras víctimas. Revista Justicia y Derecho, Santiago, v. $2, n^{\circ} 1,2019$ 
peacebuilding8 ... ya que "terminada la confrontación armada, toca reconstruir lo destruido, lo material y lo inmaterial"

Esto requiere una construcción de cultura de paz. Este autor ${ }^{10}$ propone unas acciones en la construcción integral de la paz, como los cambios de las políticas públicas que hagan frente a los problemas sociales, económicos, políticos y culturales que subyacen al conflicto en estado latente, de manera que se evite su expresión en forma violenta. La necesidad de construir estrategias de intervención de carácter más estructural y de incidencia política y movilización social para lograr que estas propuestas de cambio estructural que se traduzcan en políticas públicas efectivas.

Consolidar y profundizar las formas de contención social de los conflictos violentos, realizando acuerdos humanitarios que se den mientras dura el conflicto en la perspectiva de contención, así como el apoyo a las víctimas de la violencia, para que tengan condiciones de hacer tránsito a volver a ser ciudadanos con capacidad para reclamar sus derechos y reconstruir su proyecto de vida.

Invita a aprender de la experiencia de los procesos de paz, tanto de los que tuvieron éxito como los que fallaron ${ }^{11}$. En cuanto a las prácticas en el postconflicto, esta tesis propende por la implementación trasformadora y restaurativa para las víctimas, no solo de las condiciones que generaron su estatus, sino además la protección absoluta en su retorno y recuperación económica.

Para la consecución de las anteriores metas pro víctimas, la administración y la política se deben trasformar, fortaleciéndose en sus instituciones con el complemento del estamento judicial y la restauración total del estado democrático que funcionaba antes de los hechos consolidatorios de la violencia sistemática, hace énfasis en "la estrategia de repensar en el postconflicto el gasto militar, y la reinserción y frente a la comunidad internacional la consecución de recursos para el apoyo a la construcción de la paz, participación en facilitación, mediación y verificación"12.

Avizoró para Colombia, la Justicia Transicional, valioso aporte por medio del cual estableció sus límites para alcanzar plenamente las demandas de las víctimas a la verdad, la justicia y la reparación y ahondar además, en una política de paz, que haga frente a todo tipo de exclusiones, en particular a las de género, generaciones, orientación sexual y raza.

La Justicia Transicional pensada por García para Colombia, y como se explicará, con algunas variables, es la que se pactó, tanto la concebida desde un sistema que involucra además de lo judicial, aspectos restaurativos y prospectivos, alrededor de las víctimas presentes del conflictos y las futuras del pos-acuerdo, como la complementaria de mantenimiento de la paz-peacekeeping-para preservarla de una recaída en términos de evitar a toda costa el resurgimiento de las causales subyacentes (Tiene que ver con las genitoras de la violencia directa, esto es, la violencia estructural o indirecta y la violencia cultural o simbólica que admite como normal al punto de legitimación de las dos anteriores) y que involucra a la sociedad en todos sus estadios cronológicos incluyendo a la generación presente y futura.

\subsection{Crisis de lo colectivo en épocas de individualismo}

La paz en el pos-acuerdo de naturaleza colectiva de la paz y como derecho de segunda generación

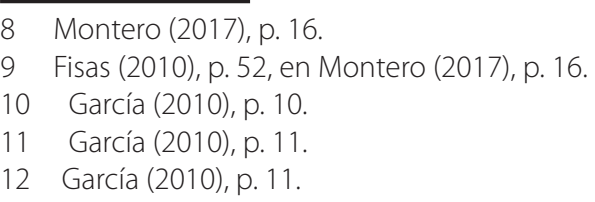

MUÑOZ HERNÁNDEZ, Luis Antonio. Compromiso de no repetición del Estado colombiano, en el Pos-Acuerdo 2016, una forma de reparación en transición, para las FARC-EP y las nuevas y futuras víctimas. Revista Justicia y Derecho, Santiago, v. $2, n^{\circ} 1,2019$ 
involucra un constante diálogo entre Estado y ciudadanía, desde lo individual y desde lo grupal y colectivo, incluyendo el colectivo denominado generación futura. Esto de por sí, amerita un sacrificio individual en todos los aspectos contraria de la filosofía política, económica y social de sociedades occidentales como la Colombiana. El obstáculo entonces no es de poca monta.

Veamos esta circunstancia tomando como base al sociólogo polaco Zygmunt Bauman¹3, la implementación de todas esas herramientas de justicia transicional que involucra en todo sus contextos la relación Sociedad - Estado más cercana y de libre discusión, encuentra una dificultad: una relación tradicional, acostumbrada a estructuras sin discusión, un no control entre la función del estado y la Libertad del individuo.

Bauman en su obra "En busca de la Política" analiza el modelo de gobierno estatal denominado "la democracia liberal14. En un contexto político e histórico post revolución francesa, razona y critica este modelo de gobierno instituido a finales del siglo XVIII, al que califica como una utopía consistente en el intento de llevar a cabo un equilibrio entre Estado y Sociedad, lo que dista considerablemente de lo que es la democracia real. Se concibió al Estado, como "... un intento de mantener la efectividad como guardián de la paz y mediador entre los intereses particulares y grupales"15, de tal suerte que le permita al Estado manejar sus asuntos, a la sociedad manejar los suyos, y al mismo Estado, instrumentos para repeler los excesos de la sociedad. En su crítica Bauman, cree que es una utopía tratar de conciliar eurítmicamente la libertad de los individuos para elegir la forma de vida que prefieren con la efectividad del Estado para conservar la armonía, convirtiendo "la libertad de cada uno de ellos en condición necesaria de la libertad de los otros"16 Para la democracia liberal, el incremento de estas libertades sostiene este equilibrio.

Desde estas libertades, Bauman hace hincapié en la apatía que puede llegar a tener la sociedad civil por la sociedad política y el Estado y consecuencialmente la falta de interés del Estado en resolver los asuntos de la sociedad civil. En este aspecto reflexiona sobre que la sociedad civil tiene sus esplendores y sus rasgos no tan maravillosos al dejar sin vigilancia, a su suerte al estado y a la política estatal.

Deja claro la degeneración del verdadero concepto de democracia liberal en la sociedad, argumentando su punto en decir que "El ciudadano se trasmuta en consumidor"17 haciendo alusión a que el Estado, reconoce la prioridad y la superioridad del mercado y sus leyes, sobre los demás. Ello alejó aún más la brecha entre la idea de la democracia liberal y su versión concreta existente. Su estudio involucra dos niveles explicados así: en un primer momento se permitió el pluralismo religioso, es decir la libertad individual, luego; los derechos humanos, cada uno ejerce su libertad de elección, llegando a lo que se conoce como el hombre modular, que lo representa apoyado en Ernest Gellner a través del ejemplo de muebles; los antiguos eran modelos rígidos y compactos y se pasa a un modelo modular, que se arma por partes y se puede cambiar al gusto de la persona.

El hombre modular no tiene atributos predeterminados, muestra al hombre con cualidades móviles, que se pueden descartar con facilidad y se intercambian. Es un hombre sin esencia, pues, no se queda en un pensamiento, si no que pasa a otro y a otro. Él mismo se arma y se desarma y él es el referente de sus acciones. Por eso entra en una asociación, permanece el tiempo que desea, sin atarse a ningún compromiso y ritual y en cualquier momento sale de esa estructura, facilitando la naturaleza de la sociedad

13 Bauman, Zygmunt (1999), p. 163.

14 En el análisis de Bauman sobre la Democracia liberal va desde: cómo se concibió, cuáles sus retos, dificultades; la forma como ha venido desenvolviendo desde su nacimiento hasta el presente y las consecuencias que hoy afronta por el resultado de sus fórmulas que califica como utópicas.

15 Bauman (1999), p. 164.

16 Bauman (1999), p. 164.

17 Bauman (1999), p. 166.

MUÑOZ HERNÁNDEZ, Luis Antonio. Compromiso de no repetición del Estado colombiano, en el Pos-Acuerdo 2016, una forma de reparación en transición, para las FARC-EP y las nuevas y futuras víctimas. Revista Justicia y Derecho, Santiago, v. $2, n^{\circ} 1,2019$ 
civil o liberal-democrática, su modus vivendi sin reglas, sin opresiones estatales, ya que al no pertenecer plenamente a los grupos, no se absorbe, ni se apoltrona acomodada a un grupo único.

No obstante, por esa movilidad, desarraigo, integraciones frágiles, vulnerables y falta de pertenencia y soluciones no duraderas, el hombre modular puede caer en la incertidumbre y riesgos. Esta investigación encuentra que este distanciamiento no solo hace estragos en la sociedad presente sino en medida doble o triple a la generación futura. Una comunidad de personas presentes libres y a la vez sin interés en la protección de los derechos colectivos e incluso de otros individuos. Esta estructura no es de la esencia de una sociedad colectiva.

Para Bauman, esta crisis de lo colectivo tiene como solución la sociedad republicana hoy denominada comunidad autónoma y con control, en la medida en que la ciudadanía participa activamente en su construcción, persiguiendo un equilibrio entre la libertad del individuo y el derecho de la ciudadanos a intervenir y cooperar con las leyes que les atañen en la búsqueda del bien común, en el establecimiento del legado histórico de la nación, su sangre y el suelo, convirtiéndose en la estructura que fusiona a los individuos en una comunidad llamada comunidad republicana, con capacidad de realizar sus propias leyes y de reflexionar sobre su cotidianidad, en forma colectiva con individuos autónomos.

\subsection{La paz, su naturaleza y la reparación consagrada en el acuerdo}

No es camino fácil, para una sociedad individualista como la colombiana, asimilar un acuerdo de paz en donde convergen para el pos-acuerdo todas las posibilidades extra-individuales de reparación y por ello se justifican trabajos como el presente, donde se pretende mostrar estos matices y justificar desde la Constitución Política de Colombia, la dimensión del pacto del 24 de noviembre de 2016.

\subsubsection{La paz $^{18}$}

Se ha pensado desde la visión unívoca pensada por muchos años entre paz = justicia; no paz = injusticia, paz es un estado de justica o, donde impere el orden y la justicia en el sentido de la aplicación estricta del derecho codificado que cohíbe y prohíbe conductas para mantener el orden. Esta univocidad si bien no se descarta por tener una justificación en la ley, se queda corta ante la complejidad de lo que representa la paz. Del mismo modo, se conciben como antónimos los conceptos paz y conflicto, es decir si se está en paz = no conflicto y por el contrario, si se está en conflicto = no paz. O así: no paz = violencia o conflicto; o, paz = ausencia de violencia o conflicto. Esto no es del todo cierto.

La violencia es un estado diferente al conflicto, dado que esta es solo una de las formas de abordar el conflicto. Mientras que el conflicto, per ce no es violento, sino una diferencia intra-personal; interpersonal, intra-grupal o inter-grupal, de intereses, anhelos, posiciones, gustos, etcétera, que se puede abordar con el diálogo, el arreglo directo, la indiferencia, la convención, conciliación, la hertero-composición o la violencia, forma autocompositiva donde impera la fuerza y el sometimiento de facto, de uno sobre el otro. Entonces, el conflicto es tan solo una incompatibilidad de intereses o de anhelos, desde cualquier

18 Existen algunas coincidencias con, apartes del artículo inédito de autoría del suscrito y de la Profesora Sirley Juliana Agudelo Ibáñez, denominado: "EL DERECHO HUMANO A LA PAZ Y LA JUSTICIA TRANSICIONAL FUNDANTES DE LA REPARACIÓN EN EL POSACUERDO FARC-EP - ESTADO COLOMBIANO (2016)", que también es resultado parcial de la investigación que se lleva a cabo dentro del proyecto para optar por el título de Doctor en Derecho Procesal Contemporáneo, denominado: "Formulación del Debido Proceso de Paz para Colombia desde la tensión: justicia transicional - Justicia Retributiva de cara a la Paz Prospectiva.", de la Universidad de Medellín Colombia. Como los resultados son diferentes lo inédito no se afecta. Se consulta porque debe existir coherencia sobre estos aspectos conceptuales consultados, con una misma autoría.

MUÑOZ HERNÁNDEZ, Luis Antonio. Compromiso de no repetición del Estado colombiano, en el Pos-Acuerdo 2016, una forma de reparación en transición, para las FARC-EP y las nuevas y futuras víctimas. Revista Justicia y Derecho, Santiago, v. $2, \mathrm{n}^{\circ} 1,2019$ 
óptica de la vida y es consubstancial al ser humano ${ }^{19}$.

Sobre paz se ha dicho mucho y a lo largo de la historia también se concibe desde una solo óptica, por ejemplo, Pax Sumérica, en los inicios de la civilización, en la ciudad Uruk, conocida como la primera ciudad sumeria y humana que gozó por cerca de setecientos años de ausencia de $\operatorname{conflictos}^{20}$. La paz en Grecia, más protectora del bien común que del individual Eirene la paz como un estado ausencia de actividades bélicas entre las ciudades estado griegas, es decir, había un clima de tranquilidad y de sosiego entre las comunidades. Y la Pax Romana, como la "ausencia de conflictos y rebeliones violentas dentro de los límites del Imperio Romano controlado por un poderoso aparato militar"21, entre muchas.

En Colombia, ". . la paz es concebida de manera unívoca como la negación de la violencia directa y/o de la guerra"22. Galtung considera al "ser humano sujeto con capacidad de paz"23, tiene dentro de sus capacidades la paz, la debe buscarla y mantenerla. Concibe además la violencia desde tres dimensiones: la violencia directa, la violencia estructural y la violencia cultural. La directa que es para muchos la única, son actos de agresión física, verbal o sicológica que van en detrimento en gran porcentaje de la integridad personal directa. Aquí los seres humanos se ven influidos de tal manera que sus realizaciones afectivas somáticas o mentales están por debajo de sus realizaciones potenciales ${ }^{24}$. El estudio de la paz, apartándose de la estructura de Galtung como sucede cotidianamente en Colombia hace que se tenga una idea equivocada de ella "Al solo concebirse como única la violencia directa, entonces, el centro que tiene como paradigma a la paz como ausencia de esta violencia, es una equivocación"25.

La violencia estructural que es un tipo de violencia indirecta presente en la injusticia social y otras circunstancias que en definitiva hacen que muchas de las necesidades humanas de la población no sean satisfechas, cuando, con otros criterios de funcionamiento y organización lo serían fácilmente ${ }^{26}$, esta concepción la podemos identificar desde el estatus de la paz como de segunda generación, concebida por la Constitución Política de 1991.

La violencia cultural intenta comprender todas las facetas culturales que de una u otra forma, apoyan y justifican las realidades y prácticas de la violencia. Si la violencia directa se concibe desde su agresor y a indirecta desde el sistema, la cultural, desde las ideas, las normas, los valores, la cultura, la tradición, como alegato o aceptación natural de las situaciones provocada por ella27.

La discriminación conceptual de la violencia, también pueden expresar diferentes posiciones y circunstancias que determina una clasificación de la paz, que no se excluyen sino que se complementan. La Paz negativa, la que más se pone en práctica, consiste en la negación de la violencia directa, concepto que nace en la segunda posguerra, vista como la ausencia de guerra, entendida como guerra entre Estados. La paz positiva como ausencia de violencia estructural o indirecta mirada así cuando no existen desigualdades entre los individuos y sus estructuras sociales y hace su aparición en los años sesenta del siglo XX. En esta década comienza la interacción entre paz y desarrollo28.

Los estudios de paz y los conflictos desde la academia y la disciplina de la investigación para la paz,

19 Muñoz (2012), p. 53.

20 Muñoz y López (2000), p. 63.

21 Caireta \& Barbeito (2005), p. 15.

22 Muñoz y Agudelo (2016), p. 120.

23 Calderón (2009), p. 64.

24 Galtung, en Jiménez y López (2007), p. 115.

25 Muñoz (2012), p. 51.

26 Jiménez y López (2007), p. 117.

27 Jiménez y López (2007), p. 121.

28 Jiménez y López (2007), p. 54.

MUÑOZ HERNÁNDEZ, Luis Antonio. Compromiso de no repetición del Estado colombiano, en el Pos-Acuerdo 2016, una forma de reparación en transición, para las FARC-EP y las nuevas y futuras víctimas. Revista Justicia y Derecho, Santiago, v. $2, \mathrm{n}^{\circ} 1,2019$ 
también sitúan tres estados relacionados con la violencia: la no violencia; la no-violencia y la noviolencia. La no violencia se relaciona con la a-violencia, esto es, situaciones sin violencia física o directa. La forma no-violencia, se origina en la forma de protesta y contestación de los seguidores de Ganghi en India y fue practicada también en Suráfrica ${ }^{29}$. "Las formas de boicot, la resistencia pacífica y la no cooperación, etc., la acabaron identificando con la no-violencia, porque no era ni pura ausencia de violencia, ni pura obediencia política"30. Y la no violencia que se comenzó a desarrollar desde los años 30 "como una concepción humanista, espiritual y abierta de las relaciones humanas conflictivas. (...) un programa constructivo y abierto de tipo ético - político social y económico de emancipación y justica que pretendía, al máximo de lo posible evitar el sufrimiento humano"31. Va más allá a una simple negación de la violencia.

Cuando el discurso de la paz se traduce en alcanzar la felicidad, la tranquilidad y la serenidad, para Pasillas ${ }^{32}$, este tipo de concepción de la paz, la desnaturaliza, por ser lúdica e ideal, abstraída de la cotidianidad humana y su entorno, con naturales problemas y conflictos; en este sentido, concibe esta clase de percepción de la paz como un concepto "demasiado vago, emocional y manipulable, aunque, a la vez, nos suscita a todos un ideal, una ilusión y un presentimiento de una condición de vida y convivencia deseable y digna de nuestro esfuerzo y entrega"33. Sin embargo, solo se queda en la paz negativa, violencia - guerra, heredado de la elaborada en los orígenes de la civilización griega y romana.

\subsubsection{Naturaleza jurídica y constitucional de la paz en Colombia}

La paz como concepto y como noción jurídica, sociológica y de realismo político, quedó condensada y plasmada en todo el plenario constitucional en Colombia. Se puede decir, que la constitución misma es un acuerdo de paz. Basta con otear a través de la historia, que la Constitución de 1991 en Colombia, es un contenido transicional, buscado en forma estructural por la situación político criminal y de inestabilidad democrática en la época y en forma coyuntural con el Acuerdo de paz firmado con el grupo guerrillero

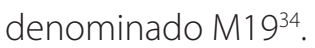

Esta es su transversalidad: la Constitución Política de Colombia en su artículo 22 establece que "La paz es un derecho y un deber de obligatorio cumplimiento" como un derecho y un deber colectivo, ubicado en el título II, Capítulo I (De los derechos fundamentales). Pero además, el preámbulo, establece la paz como un fin para el nuevo orden constitucional. En el título II, Capítulo II (De los derechos sociales, económicos y culturales) artículo 67 se consagra la paz en función de la educación. En el título II, Capítulo $\checkmark$ (De los deberes y derechos) artículo 95 la paz es una obligación perenne de la sociedad y no solo del Estado. En el título VII, capitulo 1, artículo 189 núm.7, la paz es un instrumento decisorio desde la violencia directa, para que el Presidente de la República pueda declarar la guerra; pero además, la paz, siendo el presidente el único que puede convenir y ratificar tratados de paz. En el título VII, capítulo 7 (De la policía), artículo 218, la paz es un deber y la finalidad de la policía para asegurar la convivencia en paz de las personas. En el título XII, capítulo 1 (De las disposiciones generales), artículo 338, la paz dentro del sistema fiscal

\footnotetext{
29 Jiménez y López (2007), p. 183.

30 Jiménez y López (2007), p. 183.

31 Jiménez y López (2007), p. 183.

32 Pasillas (2002).

33 Pasillas (2002), p. 5.

34 El Movimiento 19 de Abril M-19, fue un movimiento insurgente colombiano nacido a raíz del supuesto fraude electoral en las elecciones presidenciales del 19 de abril de 1970 que dieron como ganador a Misael Pastrana Borrero, contra el entonces candidato a la presidencia, general Gustavo Rojas Pinilla. En 1974, los representantes del ala socialista de la ANAPO (Alianza nacional popular), Jaime Bateman, Álvaro Fayad, Iván Marino Ospina y Luis Otero Cifuentes, junto con Carlos Toledo Plata, Israel Santamaría, Andrés Almarales, Everth Bustamante, e Iván Jaramillo conformaron el 'Movimiento 19 de abril'. Su origen fue un movimiento político y ante los sucesos mencionados se vuelve un movimiento armado. En 1990, el Estado Colombiano y el M-19 firman la Paz. Hoy sus exintegrantes han sido protagonistas de la dinámica democrática y política en Colombia.
}

MUÑOZ HERNÁNDEZ, Luis Antonio. Compromiso de no repetición del Estado colombiano, en el Pos-Acuerdo 2016, una forma de reparación en transición, para las FARC-EP y las nuevas y futuras víctimas. Revista Justicia y Derecho, Santiago, v. $2, n^{\circ} 1,2019$ 
colombiano es vista desde la violencia directa como tiempo propicio para la imposición de tributos: el Congreso, las asambleas departamentales y los concejos distritales y municipales. En el título XII, capítulo 2 (Del presupuesto), artículo 345, en tiempo de paz, no se puede fijar impuesto o contribución que no exista en el presupuesto de rentas, ni egresos al tesoro público que no estén en el presupuesto de gastos.

Demostrada la trazabilidad del concepto Paz en la Constitución de 1991, ella también se encuentra en la siguiente normativa: Acto legislativo 01 de 2016. A nivel infra-constitucional: Ley 104 de 1993 derogada por la Ley 418 de 1997; Ley 251 de 1995; Ley 438 de 1998; Ley 497 de 1999; Ley 975 de 2005; Ley 1592 de 2012; la Ley 1156 de 2007; Ley 1448 de 2011; Decreto 1038 de 2015; Ley 1779 de 2016; Ley 1820 de 2016; Decretos con fuerza de Ley 871 y 882 a 903 del 29 de mayo de 2017, ley 1908 de 2018.

También en el plano internacional, el derecho a la paz forma parte de los tratados internacionales, como la Carta de las Naciones Unidas en su apartado inicial del Preámbulo y en el artículo 26; en la Declaración Universal de Derechos Humanos; igualmente, en el Preámbulo de la OEA, y en otros documentos del derecho público internacional. Como se

observa, es un derecho colectivo pero también de segunda generación, dado que su contenido garantiza entre otros el derecho a la seguridad social y a obtener la satisfacción de los derechos económicos, sociales y culturales; al trabajo en condiciones equitativas y satisfactorias; a formar sindicatos para la defensa de sus intereses; a un nivel de vida adecuado que le asegure a la persona y a su familia la salud, alimentación, vestido, vivienda, asistencia médica y los servicios sociales necesarios; a la salud física y mental; durante la maternidad y la infancia toda persona tiene derecho a cuidados y asistencia especial; toda persona tiene derecho a la educación en sus diversas modalidades; la educación primaria y secundaria es obligatoria y gratuita.

La Corte Constitucional colombiana en su sentencia T-008 de 1992, resalta como características del derecho a la paz las siguientes: un derecho de tercera generación; Si bien es cierto se resalta la dignidad humana, ésta no puede verse individualmente, sino de manera global que encierra la humanidad; tiene un carácter solidario por que exige la concurrencia de toda la sociedad para su alcance y efectividad; es un derecho con soporte en el derecho internacional público. En el mismo sentido la Sentencia C-048 e 2001, reafirma lo expuesto por la Constitución misma, con una triple naturaleza jurídica de valor, derecho y deber con raigambre superior. La línea jurisprudencial se mantiene y ya en épocas de diálogos y del acuerdo de paz, la Sentencia C-379 de 2016 la reafirma como uno de los fines del Estado y la C-699 de 2016, sobre la constitucionalidad de los artículos 1 y 2 (parciales) del Acto Legislativo 01 de 2016, la reafirma como un deber constitucional, como un imperativo que debe concretarse.

\subsection{Justicia de transición}

Es la que se aplica con herramientas jurídicas, sociales, políticas y bajo estándares internacionales de Verdad, Justicia, Reparación y compromiso de No repetición, con el único fin de hacer de puente entre la cesación de un estado sistemático y masivo de violación de derechos humanos por causas atribuibles a un conflicto armado interno o de una dictadora o gobierno de facto y la democracia. Esta Justicia, si la cesación del estado sistemático de violaciones es producto de un acuerdo como lo es, el caso colombiano con la firma del acuerdo entre el Estado de Colombia y las Fuerzas Armadas Revolucionarias de Colombia-Ejército del Pueblo (FARC-EP) el pasado 24 de noviembre de 2016, se diseña, desde las mismas conversaciones, contrario sería que quien la diseñe sea la parte que derrote militarmente al otro bando.

Es oportuno traer el concepto de Justicia Transicional, del sociólogo noruego Jon Elster. El afirma que: “(...) la justicia transicional está compuesta de los procesos penales, de depuración y de reparación que 
tienen lugar después de la transición de un régimen político a otro"35 y sostiene que "la intensidad de la demanda de retribución disminuye con el intervalo de tiempo entre las atrocidades y la transición, y entre la transición y los procesos judiciales" ${ }^{\prime \prime 36}$. La Justicia Transicional para Tania Rincón ${ }^{37}$, responde a una concepción de la justicia vinculada a los momentos de transición política de una situación de dictadura hacia la democracia o de una situación de conflicto armado o de guerra civil hacia la paz, que busca lidiar con el pasado de graves violaciones de derechos humanos y/o del DIH, enfrentando los crímenes cometidos bajo regímenes represores o durante el conflicto armado o la guerra civil. La anterior definición, solo enfatiza el protagonismo de la justicia y la política para su reconvención en una retoma de la democracia, que bien puede adaptarse a una transición con o sin los estándares internacionales de Verdad, Reparación y No Repetición.

La Corte Constitucional indica qué puede entenderse por justicia transicional, según la Sentencia C-052/2012 38 , como aquella:

... institución jurídica a través de la cual se pretende integrar diversos esfuerzos, que aplican las sociedades para enfrentar las consecuencias de violaciones masivas y abusos generalizados o sistemáticos en materia de derechos humanos, sufridos en un conflicto, hacia una etapa constructiva de paz, respeto, reconciliación y consolidación de la democracia, situaciones de excepción frente a lo que resultaría de la aplicación de las instituciones penales corrientes.

El concepto "justicia transicional" para Uprinmy \& otros ${ }^{39}$ refiere

... a los procesos a través de los cuales se realizan transformaciones radicales de un orden social y político, bien sea por el paso de un régimen dictatorial a uno democrático, bien por la finalización de un conflicto interno armado y la consecución de la paz ${ }^{40}$.

Pero además, es posible una la Justicia de Transición precediendo a un estado democrático normal. Es la impuesta por ejemplo por un gobierno legítimo pero que de facto, reacomoda la arquitectura del Estado para legitimarse desde la no democracia, desde la expedición de leyes a su condición y sobre todo aplicando justicia dura contra quienes obstruyan el paso en su camino al gobierno de hecho y llegar a un estado sistemático de violación de derechos humanos, llamada por esta investigación como una sub Justicia transicional.

En Colombia, se puede hablar hoy, de un estado jurídico-político de pre-pos acuerdo y de pre-justicia transicional, dado que las condiciones legales y constitucionales, pese a tener un norte definido en el acuerdo de noviembre de 2016 mismo, aún no ha terminado. Esas condiciones iniciales para el desarrollo e implementación de la Justica Transicional restaurativa y prospectiva, como la ley estatutaria de la justicia transicional y la integración de las Salas y el Tribunal de Paz de dicho sistema, aun cuando a la fecha ya la Corte constitucional, en comunicado del 17 de agosto de 2018 ha declarado exequible la ley estatutaria sin que se conozca su texto; Determinar el o los periodos de transición, las condiciones seguridad de su implementación respecto de guerrilleros de las FARC -EP que no firmaron; la presencia del Estado en sitios donde el orden estaba a cargo de este grupo guerrillero, el manejo ambiental y los ahora llamados grupos armados organizados G.A.O. (antes Bandas Criminales -BRACRIM), no obstante los decretos con fuerza de ley del ejecutivo del 29 de mayo de $2017^{41}$, no han terminado. Ello da lugar discusiones respec-

35 Elster (2004), p. 15.

36 Elster (2004), p. 97.

37 Rincón (2010), p. 26.

38 Agudelo y Muñoz Hernández (2016), Sentencia C-052/2012.

39 Uprinmy et al. (2005), p.13

40 Uprinmy et al. (2005), p. 13.

41 Decretos con fuerza de Ley 871 y 882 a 903 del 29 de mayo de 2017.

MUÑOZ HERNÁNDEZ, Luis Antonio. Compromiso de no repetición del Estado colombiano, en el Pos-Acuerdo 2016, una forma de reparación en transición, para las FARC-EP y las nuevas y futuras víctimas. Revista Justicia y Derecho, Santiago, v. $2, n^{\circ} 1,2019$ 
to de, cómo calificar a las víctimas de este interregno, si nuevas víctimas del pos-acuerdo y aún víctimas del conflicto. Para esta investigación las nuevas víctimas son del pos-acuerdo.

La Justicia transicional entonces, hace parte integral de la última etapa del acuerdo.

"(...) la etapa final del conflicto, conocida como posconflicto, es en la que se materializará efectivamente la paz, etapa que será la más larga y la que tendrá los mayores retos, desafíos y obstáculos para transformar el conflicto armado colombiano y evitar que éste vuelva a reaparecer con la misma intensidad"42.

Termina esta primera sección: la postura epistemológica analítica y critica de: paz, los conflictos y la violencia, así como la naturaleza jurídica y Constitucional de la Paz y la razón de ser y los estadios de la Justicia Transicional en general y en la Colombia actual. Ahora, el tratamiento a la Reparación integral en el pos-acuerdo, sus víctimas y su modalidad de no repetición.

\subsection{La reparación}

Desde la óptica del derecho colectivo de la paz y las acciones públicas por parte del Estado Colombiano, en desarrrollo de los derechos de segunda generación su base, dado que conjura situaciones mas que de violencia directa, la estructural ya explicada por ausencia de garantía para suplir as necesidades básicas, y cuyo generador por regla es el mismo Estado; la reparación, que no indemnización desde el derecho privado, prevé por su naturaleza, solo un ingrediente pequeño de carácter individualista, la indemnización y otros aspectos que van más allá de la compensación económica, esto es, no solo atiende el patrimonio individual de la víctima, sino además, por el valor supremo, el principio y el derecho humano de la paz, la subyacencia de ese estado sistemático e insalvable de violación de derechos humanos, desde lo colectivo o grupal a la cual pertenece esa individualidad. Y la base normativa, son los artículos, 1,2 y 25 de la Ley 1448 de $2011^{43}$.

\subsubsection{La reparación en el acuerdo FARC-EP - Estado colombiano (2016)}

El Acuerdo de Paz celebrado entre el grupo guerrillero FARC-EP y el Estado Colombiano el 24 de noviembre de 2016 establece una Justicia Transicional Restaurativa, Transformadora y Prospectiva. La reparación integral acordada tiene las siguientes características: Se concibe desde el Derecho Colectivo de la Paz y no desde el individualismo, como sucede en las pretensiones que contra particulares o el Estado se reclaman en demandas de responsabilidad civil. Hace parte de la justicia transicional y del sistema integral de Justicia, Verdad, Reparación y Compromiso de no repetición -S.I.V.J.R.NR.- garantizado por el componente extrajudicial de "Medidas de Reparación Integral, sin el presupuesto de una sentencia de responsabilidad de los victimarios. Por ello, su participación en la Jurisdicción Especial para la Paz será exigua y limitada.

Los componentes de reparación además de la mínima indemnización, son de restitución, indemnización, rehabilitación, satisfacción y garantías de no repetición, en sus dimensiones individual, colectiva,

42 Calderón (2016), p. 227-257.

43 Ley de Víctimas y restitución de tierras. "Artículo 25 de la ley 1448 de 2011: "Derecho A La Reparación Integral. Las víctimas tienen derecho a ser reparadas de manera adecuada, diferenciada, transformadora y efectiva por el daño que han sufrido como consecuencia de las violaciones de que trata el artículo $3^{\circ}$ de la presente Ley. La reparación comprende las medidas de restitución, indemnización, rehabilitación, satisfacción y garantías de no repetición, en sus dimensiones individual, colectiva, material, moral y simbólica. Cada una de estas medidas será implementada a favor de la víctima dependiendo de la vulneración en sus derechos y las características del hecho victimizante." (...)"'."

MUÑOZ HERNÁNDEZ, Luis Antonio. Compromiso de no repetición del Estado colombiano, en el Pos-Acuerdo 2016, una forma de reparación en transición, para las FARC-EP y las nuevas y futuras víctimas. Revista Justicia y Derecho, Santiago, v. $2, n^{\circ} 1,2019$ 
material, moral y simbólica. medidas de asistencia adicionales complementarias a las medidas de reparación al aumentar su impacto en la población beneficiaria; como se observa, más holísticos, solidarios, colectivos, integrales, de progreso, todo ello con enfoque determinante en resolver y transformar la causas que desataron el daño causado y que afectan en forma directa e indirecta, derechos concomitantes de segunda generación, y que son el soporte del de tercera generación a la paz, como el acceso a la educación, salud, vivienda, servicios de saneamiento básico, acceso vial a sus territorios.

Se sustenta además de la legislación comentada, el preámbulo del acuerdo del 24 de noviembre de 2016 Inciso 4 de la página tres: "(...)."...las causas históricas del conflicto, como la cuestión no resuelta de la propiedad sobre la tierra y particularmente su concentración, la exclusión del campesinado y el atraso de las comunidades rurales, que afecta especialmente a las mujeres, niñas y niños." (...)". Otra justificación de la naturaleza y cualificación jurídica y de realismo político, para esta clase de reparación desde la paz, además de las bases teóricas de justicia restaurativa, sentadas en líneas anteriores, es la Justicia Transicional prospectiva pactada y consagrada el preámbulo del acuerdo:

"(...)" .. Exaltando y consagrando la justicia prospectiva en tanto reconoce derechos fundamentales esenciales para las nuevas y futuras generaciones como son el derecho a una tierra conservada, el derecho a la preservación de la especie humana, el derecho a conocer sus orígenes y su identidad, el derecho a conocer la verdad sobre hechos acontecidos antes de su nacimiento, el derecho a la exención de responsabilidades por las acciones cometidas por las generaciones precedentes, el derecho a la preservación de la libertad de opción, y otros derechos, sin perjuicio de los derechos de las víctimas de cualquier edad o generación a la verdad, la justicia y la reparación;" "(... .). Preámbulo del acuerdo del 24 de noviembre de 2016 Inciso 7 de la página tres (subrayado fuera del texto).

Con esto, no solo se sustenta la reparación integral con el compromiso de la víctima de ceder en su interés particular, para la reparación en interés general de su entorno, sino que guarda equilibrio con la generación futura, evitando así su victimización antes de nacer, en términos de violencia estructural.

\subsection{Las victimas del Pos-Acuerdo y su reparación.}

Son aquellas que no están en el acuerdo; pero hacen parte de la etapa final del proceso o pos-acuerdo, para el caso colombiano, desde el 24 de noviembre de 2016 en adelante. ¿Cuáles pueden ser las nuevas víctimas? Primero, las del acuerdo pero re-victimizadas en el pos acuerdo e implementación no solo son víctimas del conflicto en vías de reparación sino lo pueden volver a ser. ¿Y cuáles sus victimarios? Por regla general, El Estado y la misma sociedad en su dinámica, si persiste las causas que generaron la violencia estructural y cultural promotoras de la directa, esto es, el daño generado por la desigualdad y exclusión social, la las necesidades básicas insatisfechas ¿ Y qué solución de reparación? la reparación integral en sí, que de darse como está concebida por el Acuerdo de paz y el artículo 25 de la Ley 1448 de 2011, pre-daño directo, que se evita con la no repetición, como reparación integral, acorde con la naturaleza de ser de la Paz como Derecho Colectivo, invirtiendo la teoría de la responsabilidad por daños que en materia de derechos colectivos se deben prevenir, esto es, que su reparación no requiere de la presencia del daño, sino aplicando la precaución por la vía del compromiso de la no repetición.

Segundo, de un lado los ex combatientes de las FARC - EP; también los particulares organizados o no, defensores de derechos humanos; que participan en la implementación del acuerdo de paz, así como las personas jurídicas de derecho privado y las de derecho público que participan en la implementación del acuerdo de paz y la generación futura. ¿Y cuáles sus victimarios? El Estado, por conducto de las fuerzas del orden directa o indirectamente; el paramilitarismo, las fuerzas que resurgen y sus redes de apoyo; otras organizaciones o grupos armados organizados G.A.O.; cualquier persona que presente conductas

MUÑOZ HERNÁNDEZ, Luis Antonio. Compromiso de no repetición del Estado colombiano, en el Pos-Acuerdo 2016, una forma de reparación en transición, para las FARC-EP y las nuevas y futuras víctimas. Revista Justicia y Derecho, Santiago, v. $2, n^{\circ} 1,2019$ 
criminales como homicidio, masacres que atenten contra defensores de derechos humanos; movimientos sociales; movimientos políticos y/o personas que participen en la implementación de los acuerdos y en la consecución de la paz estable y duradera. ¿Y qué hay que hacer con estas nuevas víctimas, si no está cualificada por el acuerdo dado que no son víctimas del conflicto sino del llamado pos-conflicto o pos-acuerdo? Una solución jurídica post-daño, sería aplicar por extensión, el instituto del derecho privado colombiano conocido como el pos contrato, en donde, se es responsable y se debe reparar a las víctimas de un conflicto que, si bien se extinguió por el acuerdo, perviven obligaciones al futuro de la firma por situaciones ínsitas a él.

\section{¿Qué clase de violencia además de la ya mencionada de persistir la subyacencia, se puede pre- sentar en el pos-acuerdo a estas víctimas nuevas, incluyendo a los desmovilizados? Además de lo ya mencionado, las nuevas víctimas de violencia directa, tanto las presentes, como la generación futura derivadas directamente del acuerdo y su implementación; la historia reporta consecuencias a partir de los acuerdos de paz en Latinoamérica, incluyendo Colombia y en el mundo, como el resurgimiento de grupos armados organizados, paramilitarismo o afines a ellos que victimizan los beneficiarios de estos acuerdos. El Instituto de Paz de los Estados Unidos -USIP-, ha realizado estudio sobre esta circunstancia, referenciado en la exposición de motivos del Decreto con fuerza de Ley 898 del 29 de mayo de 2017 emitido por el Presidente de la República de Colombia, de implementación de los acuerdos ${ }^{44} 454647$.}

El Decreto 898 de 2017 en su exposición de motivos, también referencia que "en el caso colombiano, grupos políticos han sido víctimas de homicidios selectivos durante procesos de transición a la vida civil. Al respecto, en 2008 el Programa Presidencial de Derechos Humanos de la Vicepresidencia de la República elaboró un informe en el que documentó que durante el período de 1984 a 1993, 540 homicidios fueron cometidos en contra de los miembros de la Unión Patriótica ${ }^{48}$, que representaron el 40\% del total de la violencia política, y el 60\% de las víctimas entre 1986 y 1987".

El actual pos acuerdo, no ha sido la excepción y ya arroja víctimas de esta naturaleza. En el informe A7HRC73473Add.3 del Alto comisionado de la ONU, también citado en el Decreto con fuerza de Ley 898 del 29 de mayo de 2017, de implementación de los acuerdos ${ }^{49}$ analiza la situación de los defensores de derechos humanos "siguió siendo motivo de preocupación". En 2016 hubo 389 ataques distribuidos en:

44 Exposición de motivos del Decreto 898 del 29 de mayo de 2017, p. 10. Expone que en los postconflictos de Irlanda (1998), donde una Comisión de Monitoreo Independiente identificó que existían dificultades, en la implementación del Acuerdo del Viernes Santo de 1998, debido a la existencia de grupos paramilitares tanto unionistas como independentistas comprometidos en actividades con el contrabando, extorsión, falsificación de productos y robos.

45 Exposición de motivos del Decreto 898 del 29 de mayo de 2017, p. 11. También referenció casos de corrupción en Bosnia y Herzegovina con posterioridad al Acuerdo de Paz de Dayton, protagonizados por partidos nacionalistas bajo la sospecha de destinar los fondos a fugitivos de guerra.

46 Exposición de motivos del Decreto 898 del 29 de mayo de 2017, p. 11. En Sudáfrica los niveles de violencia comparables a aquellos propios de la violencia política gracias al legado del apartheid y los problemas económicos.

47 Exposición de motivos del Decreto 898 del 29 de mayo de 2017, p. 11. En Sudáfrica los niveles de violencia comparables a aquellos propios de la violencia política gracias al legado del apartheid y los problemas económicos.

48 La Unión Patriótica fue el partido político en Colombia legalmente constituido en 1985 como parte de una propuesta política de varios grupos guerrilleros, entre ellos el Movimiento de Autodefensa Obrera (ADO), dos frentes desmovilizados (Simón Bolívar y Antonio Nariño) del Ejército de Liberación Nacional y las Fuerzas Armadas Revolucionarias de Colombia (FARC). Su primer Consejo Directivo fue encabezado por el Secretariado de las FARC. Con el tiempo, el partido UP tomó distancia de los grupos insurgentes y llamó a negociar una paz democrática y duradera. El Partido Comunista Colombiano (PCC) también participó en la formación y organización de la UP. No hubo paz, dos candidatos presidenciales, los abogados Jaime Pardo Leal y Bernardo Jaramillo Ossa, 8 congresistas, 13 diputados, 70 concejales, 11 alcaldes y alrededor de 5000 militantes, fueron sometidos a exterminio físico y sistemático por grupos paramilitares, miembros de las fuerzas de seguridad del Estado (ejército, policía secreta, inteligencia y policía regular) y narcotraficantes; los sobrevivientes al exterminio abandonaron el país. En julio de 2013 el Consejo de Estado le devolvió la personería jurídica a la Unión Patriótica.

49 Exposición de motivos del Decreto 898 del 29 de mayo de 2017, p. 11.

MUÑOZ HERNÁNDEZ, Luis Antonio. Compromiso de no repetición del Estado colombiano, en el Pos-Acuerdo 2016, una forma de reparación en transición, para las FARC-EP y las nuevas y futuras víctimas. Revista Justicia y Derecho, Santiago, v. $2, n^{\circ} 1,2019$ 
59 homicidios, 44 ataques y 210 amenazas y 72 violaciones a los derechos a la propiedad y la privacidad. En 2017 al momento de este estudio van 41 denuncias de homicidios (14 verificadas); continuaron en 2017 y 2018. Según el informe especial de riesgo: "Violencia y amenaza contra líderes sociales y defensores de derechos humanos" de la Defensoría del Pueblo, también citado en el Decreto Ley 898 del 29 de mayo de 2017, divulga ${ }^{50}$ del primero de enero de 2016 al 01 de marzo de 2017 hubo 194 ataques distribuidos en 156 homicidios, 33 ataques, 5 desapariciones forzadas, ratificando la grave situación de riesgo en la que se encuentran los defensores de derechos humanos y movimientos sociales en la implementación del Acuerdo Final.

Con todos estos antecedentes incluyendo el caso del Partido político Unión Patriótica, esta investigación deja por sentado que el Estado colombiano reconoció y adquiere el compromiso de no repetición, emitiendo para ello este Decreto Ley 898 del 29 de mayo de 2017, creando la Unidad Especial de Investigación adscrita a la Fiscalía General de la Nación para el desmantelamiento de las organizaciones y conductas criminales responsables de homicidios y masacres, que atentan contra defensores/as de derechos humanos, movimientos sociales o movimientos políticos o que amenacen o atenten contra las personas que participen en la implementación de los acuerdos y la construcción de la paz, incluyendo las organizaciones criminales que hayan sido denominadas como sucesoras del paramilitarismo y sus redes de apoyo, en cumplimiento a lo dispuesto en el Punto 3.4.4 del Acuerdo Final para la terminación del conflicto y la construcción de una paz estable y duradera, bajo los criterios de conexidad estricta, consagrados en este punto 3.4.4 del acuerdo de paz y el Acto Legislativo 01 de 2017 y en relación directa, con el Título I y artículo 25 numerales 1.12 y artículos 61 y 66 de este Decreto el cual también restructuró la Fiscalía General de la Nación.

La Corte Constitucional colombiana suspendió su estudio de esta disposición normativa, hasta tanto no se pronunciara frente al Acto legislativo 01 de 2017, por la estrecha relación de unidad material y de subordinación, estudio que se reanudó desde el 13 de julio del presente año 2018, cuando se publicó la Sentencia C-674 de 2017 y que para el mes de noviembre de 2017 ya se había comunicado los alcances de la exequibilidad condicionada del mencionado Acto Legislativo 001 de 2017. Pero, aún sin la publicación de la sentencia C-674 de 2017, el Congreso de la República de Colombia el 9 de julio de 2018 expide la ley 1908 por "medio de la cual, se fortalecen la investigación y judicialización, organizaciones criminales, se adoptan medidas para su sujeción a la justicia y se dictan otras disposiciones".

Esta ley fortalece el accionar y le da herramientas sustanciales e instrumentales a la recién creada por el Decreto Ley 898 de 2017, Unidad Especial de Investigación ${ }^{51}$. Es evidente que con la expedición del Decreto ley 898 del 29 de mayo de 2017 y la Ley 1908 de 2018, es claro el compromiso del Estado colombiano de reparar tanto a víctimas del conflicto y en especial las del pos-acuerdo, dentro de ellas las ex combatientes de las FARC-EP y los defensores de derechos humanos e implementadores del acuerdo, por la modalidad de la no repetición, legislación sin precedentes, animada de las negativas experiencias extrajeras y vernáculas.

50 Exposición de motivos del Decreto 898 del 29 de mayo de 2017, p. 11.

51 Esta ley 1908 de 2018, adiciona el artículo 182 A, complementa el artículo 340 y adiciona el 340 A, un parágrafo del 346, el numeral 8 del incido 3 del 365, el 188 E, modifica el artículo 347 de la ley 599 de 200, Código Penal Colombiano; y adiciona el artículo 244 A, un parágrafo del 325 y del 236, un inciso final al 242, adiciona el 242 B un parágrafo del 243, dos parágrafos del 244, un parágrafo 5 del 284, adiciona el 229 A, dos parágrafos del 297, el 212 B, 307 A, 313 A, 317 A de la ley 906 de 204 , Código de Procedimiento Penal.

MUÑOZ HERNÁNDEZ, Luis Antonio. Compromiso de no repetición del Estado colombiano, en el Pos-Acuerdo 2016, una forma de reparación en transición, para las FARC-EP y las nuevas y futuras víctimas. Revista Justicia y Derecho, Santiago, v. $2, n^{\circ} 1,2019$ 


\section{CONCLUSIONES.}

Paz y Justicia son conceptos que se analizan inicialmente desde la postura interior del ser humano. Su dificultad se evidencia cuando se exterioriza y más cuando se requiere de unidad multidimensional en el conglomerado social. El conflicto es inherente al ser humano. La violencia, que no sinónimo de conflicto es solo una de las formas de abordarlo.

La paz es concebida desde los estudios constitucionales de cara a la Constitución Política Colombiana de 1991, desde el preámbulo como un fin del Estado; y desde su articulado, como un principio que asegura la convivencia pacífica, como un derecho y deber del Estado y la sociedad, como un deber ciudadano. Además, como un derecho colectivo de tercera generación y como un derecho síntesis de segunda generación.

La Justicia Transicional garantiza la implementación y desarrollo de la etapa final del conflicto llamado pos-conflicto o pos-acuerdo. El Colombia se pactó en el Acuerdo de Paz del 24 de noviembre de 2016 una Justicia Transicional Restaurativa y Prospectiva, con sus postulados internacionales de Verdad, Reparación, Justicia y Compromiso de no repetición, acorde a los estándares de la teoría de la Paz y los Conflictos y de la naturaleza misma de la Paz como Derecho.

Lo anterior implica que la reparación a las víctimas del conflicto tengan una naturaleza jurídica diametralmente opuesta a la figura derecho privado de la indemnización. Una reparación integral para las víctimas del conflicto, las nuevas y de las generaciones futuras. La reparación integral que amalgama lo individual y lo solidario con lo colectivo, encuentran en la actual sociedad liberal un inconveniente por su excesiva libertad y falta de control del Estado hacia la ciudadanía y de la ciudadanía hacia el Estado. Para ello Bauman propone una sociedad republicada totalmente compatible, que acercaría y conciliaría estos dos extremos.

Las víctimas pueden re victimizarse si continúan las causas estructurales y culturales que engendran violencia directa. Los pos acuerdos en Latinoamérica y en mundo generan una reacción de quienes no están conformes con el estado de cosas que genera un Acuerdo de Paz, por razones ideológicas, económicas, de control territorial y político, lo que genera nuevas víctimas, en especial, aquellas involucradas en la implementación del acuerdo de paz y los mismos reinsertados o excombatientes y la generación futura. Ellas pueden ser reparadas, con la persistencia en el tiempo de la reparación integral en todos sus componentes en sí, que de darse como está concebida por el Acuerdo y el artículo 25 de la Ley 1448 de 2011, que garantiza la no repetición de la violencia estructural que anida la violencia directa y justifica la violencia cultural.

Novedad del acuerdo de paz en Colombia para el mundo en materia de Justicia Transicional: reparación por la modalidad del Compromiso de no repetición, puntualmente, con medidas efectivas como la expedición del Decreto con fuerza de Ley 898 de 2017 del 29 de mayo de 2017, creando la Unidad Especial de Investigación, en defensa de estas víctimas y en especial de los excombatientes del grupo guerrillero FARC-EP, en cumplimiento del acuerdo. 


\section{Bibliografía Citada}

Bauman, Zygmunt (1999): En busca de la Política (México, Fondo de Cultura Económica. Primera Edición).

CalReta, Marina y Barbeito, Cécile (2005): Introducción de conceptos: paz, violencia, conflicto (Cuadernos de educación para la paz) (Barcelona, España. Escola de Cultura de Pau).

CALDERón, Jonathan (2016): "Etapas del conflicto armado en Colombia: hacia el posconflicto en Latinoamérica", Revista de Estudios Latinoamericanos. Vol. 62, enero-junio: pp. 227-257.

ELSTER, Jon (2006): Transitional justice in historial perspective (2016): Rendición de cuentas: La Justicia Transicional en perspectiva histórica (trad. Zaidenwerg, Ezequiel (2006), Katz Editores, Buenos Aires).

Fisas, Vincen (2016): Anuario 2016 de procesos de paz (Icaria. Barcelona).

Galtung, Johan (2003): Paz por medios pacíficos. Paz y conflicto, desarrollo y civilización (Bilbao, Bakeaz).

García Durán, Mauricio (2010): Colombia: conflicto armado, procesos de negociación y retos para la paz (Bogotá, Colombia).

Hernández, José Gregorio (2015): Constitución Política de Colombia. Comentada (Medellin, Colombia. Edit. Dike).

Jiménez, Francisco y López, Mario (2007): Hablemos de Paz (Instituto de Investigación en Paz, Conflcito y Democracia, Pamplona, Colombia, Universidad de Pamplona).

Montero, Aitor (2017): "El proceso de "desecuritización" en el conflicto armado colombiano para la construcción de la paz", Revista Ciudad Paz-ando, 10 (1).

MuÑOz, Luis (2012): Justicia Transicional y la realidad de los procesos de paz en la construcción del nuevo orden social en Colombia (Universidad Libre de Colombia Seccional Cúcuta, Cúcuta, Colombia).

Muñoz, Luis. y Agudelo, Sirley (2016): Justicia Transicional y Sustitución Constitucional en Colombia. Caso M-19 (1990) (Medellín, Colombia, Editorial Biblioteca Jurídica Diké en coedición con Universidad Libre de Colombia Seccional Cúcuta).

Muñoz, Francisco y López, Mario (2000): Historia de la paz 2 (Granada, España, Universidad de Granada).

Pasillas, Miguel (2002): "Concepciones de "violencia" y "paz" y educación para la paz", Revista electrónica interuniversitaria de formación del profesorado, 5(2), 1-7. Universidad de la Rioja, España.

Presidencia de la Republica de Colombia (2016): Acuerdo Final para la terminación del Conflicto y la construcción de una Paz Estable y Duradera (24 noviembre de 2016) Bogotá - Colombia.

República de Colombia (1991): Asamblea Nacional Constituyente (Febrero de 1991). Biblioteca Luis Ángel Arango. Bogotá.

Rincón, Tania (2010): La Justicia Transicional y los derehcos Humanos en el derecho Internacional Humanitario, en Tania Rincón [ed], Verdad, Justicia y Reparación: La Justicia de la Justicia Transicional (Universidad del Rosario, Bogotá).

Schlesinger, Cristina (2006): "Teoría Constitucional". Liber Amicorum en homenaje a Vladimiro Naranjo (Universidad del Rosario, Bogotá). Capítulo IV. La Reforma a la Constitución Política.

Sen, Amartya (2010): La ldea de Justicia (Editorial Taurus, Buenos Aires, Argentina).

MUÑOZ HERNÁNDEZ, Luis Antonio. Compromiso de no repetición del Estado colombiano, en el Pos-Acuerdo 2016, una forma de reparación en transición, para las FARC-EP y las nuevas y futuras víctimas. Revista Justicia y Derecho, Santiago, v. 2, no 1, 2019 
Uprimny, Rodrigo., Saffon, María (2005): Estándares internacionales y procesos de paz en Colombia. Entre el Pedón y el paredon, pregunas y dilemas de justicia transicional. (Uniandes - Corcas Editores, Bogotá).

\section{NORMAS JURÍDICAS CITADAS}

Congreso de Colombia. Acto Legislativo 01 de 2012. Por medio del cual se establecen instrumentos jurídicos de justicia transicional en el marco del artículo 22 de la Constitución Política y se dictan otras disposiciones. Bogotá, 2102.

Congreso de Colombia. Acto Legislativo 01 de 2016. Por medio del cual se establecen Instrumentos Jurídicos para facilitar y asegurar la implementación y el desarrollo Normativo del Acuerdo Final para la Terminación del Conflicto y la Construcción de una Paz Estable y Duradera. Bogotá, 2016.

Congreso de Colombia. Acto legislativo 01 de 2017. Por medio del cual se crea un título de disposiciones transitorias de la Constitución para la terminación del conflicto armado y la construcción de una paz estable y duradera y se dictan otras disposiciones. Bogotá, 2017.

Decretos con fuerza de ley 871 y 882, 883, 884, 885, 886, 887, 888, 889, 890, 891, 892, 893, 894, 895, 896, 897, 898, 899, 900, 901, 902 y 903 del 29 de mayo de 2017, expedidos por el presidente de la República de Colombia bajo facultades extraordinarias para la implementación del acuerdo de paz firmado por el Estado Colombiano y el grupo insurgente FARC- EP.

Decreto 898 del 29 de mayo de 2017. Por el cual se crea al interior de la Fiscalía General de la Nación la Unidad Especial de Investigación para el desmantelamiento de las organizaciones y conductas criminales responsables de homicidios y masacres, que atentan contra defensores/as de derechos humanos, movimientos sociales o movimientos políticos o que amenacen o atenten contra las personas que participen en la implementación de los acuerdos y la construcción de la paz, incluyendo las organizaciones criminales que hayan sido denominadas como sucesoras del paramilitarismo y sus redes de apoyo, en cumplimiento a lo dispuesto en el Punto 3.4.4 del Acuerdo Final para la terminación del conflicto y la construcción de una paz estable y duradera.

Ley 1448 de 2011, de víctimas y restitución de tierra.

Ley 1820 de 2016, por medio de la cual se dictan disposiciones sobre amnistía, indulto y tratamientos penales especiales y otras disposiciones.

Ley 1908 de 2018. Por medio de la cual se fortalecen la investigación y judicialización de organizaciones criminales, se adoptan medidas para su sujeción a la justicia y se dictan otras disposiciones.

\section{JURISPRUDENCIA CITADA}

Sentencia C-052 de 2012, Corte Constitucional de Colombia, Sala Plena. MP Nilson Pinilla Pinilla. Acción de inconstitucionalidad. Expediente D-8593.

Sentencia C-379 de 2016, Corte Constitucional de Colombia. MP. Luis Ernesto Vargas Silva. Acción de inconstitucionalidad. Expediente PE-045.

MUÑOZ HERNÁNDEZ, Luis Antonio. Compromiso de no repetición del Estado colombiano, en el Pos-Acuerdo 2016, una forma de reparación en transición, para las FARC-EP y las nuevas y futuras víctimas. Revista Justicia y Derecho, Santiago, v. $2, n^{\circ} 1,2019$ 
Sentencia C-674 del 14 de noviembre de 2017. Corte Constitucional de Colombia. MP. Luis Guillermo Guerrero Pérez. Acción de inconstitucionalidad. Expediente RPZ-003.

Sentencia C-048 de 2001. Corte Constitucional, Sala Plena 24 de Enero de 2001. MP. Eduardo Montealegre Lynett. Demanda de inconstitucionalidad. Expediente D-3058.

Sentencia C-699 de 2016. Corte Constitucional, Sala Plena 13 de Diciembre de 2016. MP. Luis Guillermo Guerrero Pérez. Demanda de inconstitucionalidad, Expediente D-11601.

Sentencia C-674 de 2017. Corte Constitucional, Sala Plena 14 Noviembre de 2017. Publicada el 13 de julio de 2018 MP. Luis Guillermo Guerrero Pérez.

MUÑOZ HERNÁNDEZ, Luis Antonio. Compromiso de no repetición del Estado colombiano, en el Pos-Acuerdo 2016, una forma de reparación en transición, para las FARC-EP y las nuevas y futuras víctimas. Revista Justicia y Derecho, Santiago, v. $2, n^{\circ} 1,2019$ 